\title{
Lagged variation of moisture conditions in central Asia compared with monsoonal Asia during the last four interglacials
}

Jia Jia ${ }^{1}$, Jianhui Chen ${ }^{2, *}$, Xin Wang ${ }^{2}$, Hao $\mathrm{Lu}^{2}$, Zhiyuan Wang ${ }^{1}$, Zaijun $\mathrm{Li}^{2}$, Qiang

5 Wang $^{2}$, Yanwu Duan ${ }^{2}$, Ilhomjon Oimahmadov ${ }^{3}$, Mustafo Gadoev $^{3}$, Fahu Chen ${ }^{4,2}$

${ }^{1}$ College of Geography and Environmental Science, Zhejiang Normal University, Zhejiang 321004, China

${ }^{2}$ MOE Key Laboratory of West China's Environmental System, College of Earth and Environmental Sciences, Lanzhou University, Lanzhou 730000, China

$10{ }^{3}$ Institute of Geology, Tajik Academy of Science

${ }^{4}$ Chinese Academy of Sciences Center for Excellence in Tibetan Plateau Earth Sciences, Beijing 100101, China

* Corresponding Authors: Jianhui Chen (Email: jhchen@1zu.edu.cn)

15 Abstract: Previous research has indicated that variations in moisture conditions in arid central Asia (ACA) were out-of-phase with those of monsoonal Asia during the Holocene. In order to investigate this phenomenon, we compared the pattern of moisture variations in ACA and the region dominated by the East Asia summer monsoon (EASM) during the last four interglacials. The results indicate that moisture variations (pre) in ACA lagged those in the EASM region by 3 kyr during MIS 5, by 0 kyr during MIS 7, by 2 kyr during MIS 9, and by 5 kyr during MIS 11 . We suggest that this lagged pattern in three out of four interglacials was the result of a zonal climatic teleconnection, westerly wind intensity, and evaporation upstream. Overall, our results shed new light on the climatic variability of central Asia and its origins during the Holocene.

1. Introduction

Asia can be climatically divided into two regions: monsoon-dominated Asia which is 
characterized by a humid environment, and arid central Asia (ACA) which is characterized by an arid environment. The climate of ACA, a part of westerlies-dominated Asia, including the greater part of central Asia, northeastern Iran, and Xinjiang province in China, has shown an opposite pattern of variation to that of Southern Europe and North-central China over the last few decades (Huang et al., 2015). On the millennial scale, geological records also indicate that moisture variations also exhibited an anti-phased pattern of variation between arid central Asia (ACA) and monsoon-dominated Asia, which is typified by a wet "Little Ice Age" and a dry "Medieval Climatic Anomaly" (Chen et al., 2010a). In addition, on the multi-millennial scale, loess records reveal a persistent wetting trend during the Holocene - following a wet early Holocene - in the regions dominated by the Indian summer monsoon (ISM), and a wet mid-Holocene in the regions dominated by the East Asian summer monsoon (EASM) (Wang et al., 2013; Chen et al., 2016). Moreover, several studies have indicated that similar phenomenon occurred during previous interglacials (e.g. Huang et al., 2015; Chen et al., 2016).

In order to examine the consistency of this anti-phased pattern of behavior between ACA and the adjacent regions, we previously investigated the last interglacial, with a duration of more than $50 \mathrm{kyr}$ and which included two and a half precession cycles. Our results indicated that moisture variations in ACA lagged those of the EASM-dominated regions by 3-5 kyr (Jia et al., 2018a). In the present study, we extend the analysis of this relationship to the last four interglacial periods.

50 During the Quaternary two major climatic transitions occurred which have attracted major research attention: the mid-Pleistocene transition (MPT) at $0.8 \mathrm{Ma}$ and the mid-Brunhes event (MBE) at $0.43 \mathrm{Ma}$. The MPT was characterized by an important shift in global climate evolution from the previous dominant 41-kyr climatic cyclicity to the subsequent dominant 100-kyr cyclicity (Ruddiman et al., 1986; Berger, 1989;

55 Shackleton et al., 1990). The MBE was characterized by the complete establishment of high amplitude 100-kyr climatic cyclicity with much warmer interglacials and cooler glacials then previously (e.g. EPICA community members, 2004; Lisiecki and Raymo, 2005). The four interglacials which are the concern of the present study thus 
had similar boundary conditions to the modern Holocene interglacial and for this reason they were selected for detailed investigation.

2. Geological setting and the studied section

ACA is far from oceanic moisture sources and is therefore an arid environment. The western part of ACA contains widespread sandy desert, while the eastern part is characterized by a basin-mountain topography (Fig. 1). Precipitation occurs mainly in the mountains and adjacent areas and rarely in the basins. In the Junggar Basin, the mean annual precipitation (MAP) is less than $50 \mathrm{~mm}$, but gradually increases to more than $1000 \mathrm{~mm}$ on the northern slopes of the North Tienshan Mountains. The rivers rise in the high mountains and flow into the lakes in the arid basins.

Figure 1

Today ACA is climatically dominated by the westerlies with precipitation in most regions predominantly in winter-spring; only in the northern part is the precipitation predominantly in summer-autumn. Notably, carbon isotope records indicate that a continental dry summer climate was established by at least $1.77 \mathrm{Ma}$ (Yang and Ding, 2006).

Loess deposits are one of the most important geological archives in the region (e.g. Ding et al., 2002; Yang et al., 2006; Chen et al., 2016; Jia et al., 2018b). They are widespread on alluvial fans, river terraces, and on the piedmont slopes of the Tienshan and Pamir mountains (Frechen and Dodonov, 1998; Sun et al., 2002; Li et al., 2018), and they have preserved paleoclimatic records from the early- to the late Pleistocene (Frechen and Dodonov, 1998; Ding et al., 2002; Wang et al., 2018; Li et al., 2019). The most complete published loess record was obtained from Tajikistan (Frechen and Dodonov, 1998; Ding et al., 2002). In the present study, the Darai Kalon (DK) section was selected to retrieve a record of moisture variations of the last four interglacials. The Holocene (modern interglacial) was excluded from the study, since this interval may be eroded or partly eroded, as suggested by Frechen and Dodonov (1998). 
The DK section $\left(38^{\circ} 23^{\prime} 4^{\prime \prime} \mathrm{N}, 69^{\circ} 50^{\prime} 1^{\prime \prime} \mathrm{E}, 1561\right.$ a.m.s.l.; Fig. 1) is $176 \mathrm{~m}$ in thickness 90 and contains 29 paleosols, according to the investigation of Ding et al. (2002). The upper four paleosols were selected in the present study. Paleosols S1, S2, and S3 are pedocomplexes, which comprise 3, 2 and 2 soil layers, respectively. S4 consists of a single soil layer. The soil layers are separated from the underlying less-weathered parent material by a thin carbonate horizon. A detail stratigraphic description is given elsewhere (Dodonov et al., 2006; Jia et al., 2018b).

It is widely observed that the loess of the Chinese Loess Plateau (CLP) provides a continuous and long-term record of fluctuations in moisture conditions in the EASM-dominated region during the Quaternary (e.g. Ding et al., 1995; Guo et al., 2009; Lu et al., 2018). The Xifeng (XF) section $\left(35^{\circ} 45^{\prime} 31^{\prime \prime} \mathrm{N}, 1^{\circ} 7^{\circ} 41^{\prime} 45^{\prime \prime} \mathrm{E}, 1345\right.$ a.m.s.l.; Fig. 1), located on the northwest edge of the EASM-dominated region, is acknowledged as preserving the most complete Quaternary record (e.g. Guo et al., 2009; Hao et al., 2012; Lu et al., 2018). In this study, the upper four loess-paleosol alternations were investigated for comparison with the loess record from Tajikistan.

Grain size analysis was conducted on all of the samples using the methods of $\mathrm{Lu}$ and An (1997). After sequential removal of organic matter with $10 \% \mathrm{H}_{2} \mathrm{O}_{2}$ and carbonate with $10 \% \mathrm{HCl}$, and dispersal using $0.05 \mathrm{~N}\left(\mathrm{NaPO}_{3}\right)_{6}$, the samples were measured using a Mastersizer 2000 laser diffraction particle size analyzer with size range of $0.02-2000 \mu \mathrm{m}$.

The eolian mineral dust comprising the loess of the CLP is transported by the East Asian winter monsoon (Guo et al., 2009). Investigations of Chinese loess have revealed a close link between the grain size of loess to variations in Northern Hemisphere ice sheets effected via the Siberian High anticyclone (e.g. Ding et al., 1995; Guo et al., 2009; Hao et al., 2012, 2015). Hao et al. (2012) confirmed that this close coupling between high northern latitude cooling and increased dust activity in the deserts of the Asian interior deserts operated on timescales ranging from decadal to Earth orbital. Therefore, the grain size of Chinese loess provides independent 
evidence for ice volume changes in the Northern Hemisphere. Importantly, the loess in ACA has similar paleoenvironmental implications as Chinese loess (Ding et al., 2002). The grain-size variations of the loess of ACA and the CLP loess correspond closely to the deep sea benthic $\delta^{18} \mathrm{O}$ curve via their common linkage with Northern Hemisphere ice volume. Therefore, the chronology of the DK and XF loess sections can be established using the accepted correlation scheme between the loess grain-size record of loess and the benthic $\delta^{18} \mathrm{O}$ record of marine sediments.

The age control points are shown in Figure 2, which are locating the boundary of Marine Isotope Stage (MIS). By determine the sample location with mean value between peak and valley around soil/loess boundary, we obtained the age control points in DK and XF section. The Linear interpolation between age control points was then used to generate a final timescale. The depths and age control points are listed in Table 1. In addition, due to high climate resolution recording by Last Glacial (LG) loess in DK section, its chronology was construct by matching the NGRIP curve. The result had been published in Wang et al. (2018). Based on the resulting chronologies, grain-size time series are presented in the Figure 3, which demonstrate that the variations in grain-size in ACA and the CLP are synchronous, which is supported by the results of cross correlation analysis (Fig. 4).

Table 1

Figure 3

Figure 4

4. Climatic proxies and their implications

After air-drying in the laboratory, $5.5 \mathrm{~g}$ of powder sediment was packed into $10 \mathrm{ml}$ plastic boxes and used for magnetic susceptibility measurements. Magnetic 
susceptibility was measured at $470 \mathrm{~Hz}$ and $4700 \mathrm{~Hz}$ ( $\chi_{\mathrm{lf}}$ and $\chi_{\mathrm{hf}}$, respectively) using a $\left(\chi_{\mathrm{fd}}\right)$ was calculated as $\chi_{\mathrm{fd}}=\chi_{\mathrm{lf}}-\chi_{\mathrm{hf}}$.

The four major magnetic minerals in loess are hematite, goethite, magnetite, and maghemite (e.g. Maher, 1998; Liu et al., 2007). It had been widely observed that weakly magnetic hematite and goethite only make a small contribution to the magnetic susceptibility, while in contrast strongly magnetite and maghemite, although present in trace contents, make a large contribution (e.g. Liu et al., 2007; Wang et al., 2018). $\chi_{\mathrm{fd}}$ is extremely sensitive to the fine-grained ferrimagnetic component of loess (Liu et al., 2007), which is 20-30 nm maghemite (Liu et al., 2007; Chen et al., 2010b). According to magnetic and mineralogical evidence, it has been proposed that the fine-grained maghemite is pedogenic, and its content can be used as proxy of paleo-precipitation (e.g. Maher et al., 1995; Jia et al., 2013; Song et al., 2014). Therefore, the high $\chi_{\mathrm{fd}}$ of soil units indicates favorable soil forming conditions under a prevailing humid climate, and the low $\chi_{\mathrm{fd}}$ of soil units indicates soil formation under a prevailing dry climate.

\section{Results}

The $\chi_{\mathrm{fd}}$ of the DK section varies within the range of $0.0-18.5 \times 10^{-8} \mathrm{~m}^{3} \mathrm{~kg}^{-1}$ and of the XF section it varies within the range of $0.8-26.2 \times 10^{-8} \mathrm{~m}^{3} \mathrm{~kg}^{-1}$ (Fig. 5a). Three peaks are evident in both $\chi_{\mathrm{fd}}$ records during MIS 5, and one poorly defined peak is evident during 130-120 ka in the XF section; however, at least three soil units can be readily distinguished in the field. Since loess is also a typical eolian dust, pedogenesis must be influenced by the processes of dust deposition (such as dust accumulate rate) as well as by the local climate. In order to minimize the influence of dust deposition and make the pedogenic signal more obviously, the FFT filtering analysis has been applied on the $\chi_{\mathrm{fd}}$ curves. Due to the development of soil units contains strongly precession component, such as: three soil units developed during MIS 5, at least two soil units developed during MIS 7, two soil units developed during MIS 9, we decided to filter out the precession cycle (19-23 kyr) to do the comparative analysis between DK and 
XF records. The resulting curve exhibits three peaks which have an out-of-phase pattern of variation compared with the DK loess record (Fig. 6a). Cross-correlation analysis of loess records reveals that during 130-75 ka the precipitation variations in ACA lagged that of the EASM-dominated region by $3 \mathrm{kyr}$ (Fig. 6e). Similarly, from the KS loess record, it can be seen that: the moisture variations lagged those of the EASM-dominated region by 3-5 kyr during MIS 5 (Jia et al., 2018a).

Both loess records exhibit two peaks during MIS 7 (Fig. 5b). In the DK section $\chi_{\mathrm{fd}}$ varies within the range of $0.4-10.5 \times 10^{-8} \mathrm{~m}^{3} \mathrm{~kg}^{-1}$, and in the $\mathrm{XF}$ section it varies within the range of $0.8-26.2 \times 10^{-8} \mathrm{~m}^{3} \mathrm{~kg}^{-1}$. The filtering curve exhibited that, during this period, precipitation change in the DK section shows synchronous variation with that in XF section (Fig. 6b), which supported by cross-correlation analysis (Fig. 6f).

Unlike MIS 5 and MIS 7, which span one and a half obliquity cycles or three precession cycles, the duration of MIS 9 and 11 are much shorter, and they only include one obliquity cycle or two precession cycles. During MIS 9, the $\chi_{\mathrm{fd}}$ in the DK section varies within the range of $1.4-18.5 \times 10^{-8} \mathrm{~m}^{3} \mathrm{~kg}^{-1}$, and within the XF section within the range of $8.7-25.9 \times 10^{-8} \mathrm{~m}^{3} \mathrm{~kg}^{-1}$ (Fig. 5c). According to cross-correlation analysis, the precipitation variations in the DK section during 290-345 ka lag those of the XF record by $2 \mathrm{kyr}$ (Fig. $6 \mathrm{~g}$ ). During MIS 11, the $\chi_{\mathrm{fd}}$ in the DK section varies within the range of $0.7-9.2 \times 10^{-8} \mathrm{~m}^{3} \mathrm{~kg}^{-1}$, and in the $\mathrm{XF}$ section within the range of $9.0-21.6 \times 10^{-8} \mathrm{~m}^{3} \mathrm{~kg}^{-1}$ (Fig. $5 \mathrm{~d}$ ). The variations of $\chi_{\mathrm{fd}}$ curves are dominated by obliquity (Fig. 5d). After application of 19-23 kyr band-pass FFT filtering, two peaks are evident in both curves during (during the period 424-379 ka) (Fig. 6d). Cross-correlation analysis of the loess records suggests that during 430-385 ka in ACA, precipitation variations lagged those of the EASM-dominated region by $5 \mathrm{kyr}$ (Fig. 6g). 


\section{Discussion}

210 Previous investigations of the Holocene in ACA have proposed that climate change in central Asia tracked insolation variations (an external factor) on the orbital scale (e.g. Ding et al., 2002; Bronger, 2003); however, climate change was also forced by a series of internal factors. Climate simulations indicate that the westerly wind intensity and upstream evaporation are the dominant factor determining humidity variations in

215 ACA (Jin et al., 2012). Huang et al. (2015) emphasized the effect of a zonal climatic teleconnection in which humidity variations were anti-phased between ACA and the Indian monsoon region. There are potentially two mechanisms which can generate such as anti-phased relationship: (1) A stronger (weaker) Indian summer monsoon (ISM) can lead to northward (southward) movement of the westerlies. (2) A stronger (weaker) ISM can lead to an extended duration of the summer monsoon and a shorter duration of the westerlies influence in Tajikistan. Accordingly, a stronger (weaker) ISM results in a precipitation increase (decrease) in the ISM-dominated region, but the northward (southward) movement of the westerlies may result in a precipitation decrease (increase) in ACA.

Both the EASM and ISM are components of the Asian summer monsoon (ASM) system. However, precipitation varies in out-of-phase pattern between the EASM-dominated and ISM-dominated regions (e.g. Chen et al., 2016). Evidence from various geological archives provides strong support for this model. For example, records from the CLP exhibit synchronous but anti-phased relationships between the summer and winter monsoon in East Asia, on timescales from multi-millennial to Earth orbital (e.g. Ding et al., 1995; Guo et al., 2009; Kang et al., 2018). In contrast, stalagmite records from South China, which have a robust chronology, document that the glacial termination of the Asian summer monsoon occurred $3 \mathrm{kyr}$ earlier than that is evident in the global ice volume record (Cheng et al., 2009). In a review of previous research, Wang and Liu (2016) proposed that stalagmite oxygen isotope record was dominated by variations in the ratio of moisture from the Indian Ocean and from the Pacific Ocean, rather than by precipitation. In a comparison with the Holocene moisture pattern in the East Asian monsoon margin, it was suggested that a major 
proportion of the variance of the oxygen isotope record from Chinese caves was contributed by the Indian Monsoon signal (e.g. Chen et al., 2015). Due to the close link between the grain-size records from the CLP and Northern Hemisphere ice volume variations, the previous results reveal an out-of-phase pattern of variation in moisture conditions between the EASM-dominated and ISM-dominated regions. A well-dated high-resolution lake sediment record from North China demonstrates that the EASM-dominated region experienced a dry climate during the early Holocene, whereas the ISM-dominated region experienced a humid climate (Chen et al., 2015). The lagged response of Northern Hemisphere ice volume to insolation variations may be the major cause of the lagged response of climate change in high and mid-latitudes to insolation (e.g. Ding et al., 1995).

250 Combining the foregoing modelling and geological evidence, an out-of-phase variation of moisture conditions between ACA and the EASM-dominated region is indicated during interglacials. This scenario is supported by the results of the present study, which indicate that during the last three out of four interglacials there was a lag in moisture changes in ACA compared to the EASM-dominated region. In addition, our results contribute to an improved understanding of climate change in ACA. During MIS 9, which was a relatively cool interglacial during which the ASM was relatively weak (e.g. Guo et al., 2009; Hao et al., 2012), there was a relatively brief 2 kyr delay in moisture change. In contrast, during MIS 11, a warm interglacial with a relatively strong ASM (e.g. Guo et al., 2009; Hao et al., 2012), there was a much longer delay of $5 \mathrm{kyr}$. Our results indicate that the length of the lag was variable and related to the intensity of the ASM, with a stronger ASM corresponding to longer lag and a weaker ASM corresponding to a short lag. This phenomenon is well explained by the foregoing model.

Among the studied interglacials, MIS 7 is distinguished by synchronous moisture variations on precession component. As illustrated in Figure 7, an interglacial climate is normally characterized by a rapid increase of precipitation at the beginning with a subsequent gradual decrease (Fig. 7a-d). However, the records from the CLP indicate the reverse pattern of climatic variation: a gradual increase from the beginning of the 
interglacial and a rapid decrease at the end (Fig. 7d). Furthermore, the MIS 7 is the a gradually strengthening ASM and the relatively weak ASM in MIS 7 are both beneficial to westerlies staying in ACA during the early stage, rather than northward movement. For this reason, the moisture record in ACA exhibits a synchronous humidity variation compared to the EASM-dominated region.

Figure 6

\section{Conclusion}

We have investigated the timing of changes in moisture conditions in ACA during the last four interglacials. The results show that changes in moisture conditions in ACA lagged those of the EASM-dominated region by $3 \mathrm{kyr}$ during MIS 5, by $0 \mathrm{kyr}$ during MIS 7, by 2 kyr during MIS 9, and by 5 kyr during MIS 11. These findings support our previous conclusions regarding the timing of climate change in ACA during the Holocene and MIS 5 (e.g. Chen et al., 2016, 2019; Jia et al., 2018a), and they also show that length of the lag was variable and influenced by the intensity of the ASM and especially the ISM. The results also support the concept of a zonal climatic teleconnection (Huang et al., 2015), which results in the westerly wind intensity and evaporation upstream (Jin et al., 2012) dominating changes in humidity conditions in ACA during interglacials.

Acknowledgements: This work was supported by the National Key Research \& Development Program of China (2018YFA0606401) and National Natural Science Foundation of China (grants 41771213, 41822102).

References:

Berger, A.: Pleistocene climatic variability at astronomical frequencies, Quat. Int., 2(89), 1-14, https://doi.org/10.1016/1040-6182(89)90016-5, 1989. 
Bronger, A.: Correlation of loess-paleosol sequences in East and Central Asia with SE Central Europe: towards a continental Quaternary pedostratigraphy and paleoclimatic history, Quat. Int., 106-107, 11-31, https://doi.org/10.1016/S1040-6182(02)00159-3, 2003.

Chen, F. H., Chen, J.H., Holmes, J., Boomer, I., Austin, P., Gates, J.B., Wang, N.L., Brooks, S.J., and Zhang, J.W.: Moisture changes over the last millennium in arid central Asia: a review, synthesis and comparison with monsoon region, Quat. Sci. Rev., 29(7-8), 1055-1068, https://doi.org/10.1016/j.quascirev.2010.01.005, 2010a.

Chen, F. H., Jia, J., Chen, J.H., Li, G.Q., Zhang, X.J., Xie, H.C., Xia, D.S., Huang, W., and An, C.B.: A persistent Holocene wetting trend in arid central Asia, with wettest conditions in the late Holocene, revealed by multi-proxy analyses of loess-paleosol sequences in Xinjiang, China, Quat. Sci. Rev., 146, 134-146. https://doi.org/10.1016/j.quascirev.2016.06.002, 2016.

Chen, F.H., Chen, J.H., Huang, W., Chen, S.Q., Huang, X.Z., Jin, L.Y., Jia, J., Zhang, X.J., An, C.B., Zhang, J.W., Zhao, Y., Yu, Z.C., Zhang, R.H., Liu, J.B., Zhou, A.F., and Feng, S.: Westerlies Asia and monsoonal Asia: spatiotemporal differences in climate change and possible mechanisms on decadal to sub-orbital timescales, $\quad$ Earth $\quad$ Sci. $\quad$ Rev., $192, \quad 337-354$, https://doi.org/10.1016/j.earscirev.2019.03.005, 2019.

Chen, F.H., Xu, Q.H., Chen, J.H., Birks, H. J.B., Liu, J.B., Zhang, S.R., Jin, L.Y., An, C.B., Telford, R.J., Cao, X.Y., Wang, Z.L., Zhang, X.J., Selvaraj, K., Lu, H.Y., Li, Y.C., Zheng, Z., Wang, H.P., Zhou, A.F., Dong, G.H., Zhang, J.W., Huang, X.Z., Bloemendal, J., and Rao, Z.G.: East Asian summer monsoon precipitation variability since the last deglaciation, Sci. Rep., 5, 11186, https://doi.org/10.1038/srep11186, 2015. Characteristics and formation mechanism of pedogenic hematite in Quaternary Chinese loess and Paleosols, Catena, 81, 217-225, https://doi.org/10.1016/j.catena.2010.04.001, 2010b. 
Cheng, H., Edwards, R.L., Broecker, W.S., Denton, G.H., Kong, X.G., Wang, Y.J., https://doi.org/10.1126/science.1177840, 2009.

Ding, Z.L., Liu, T.S., Rutter, N.W., Yu, Z.W., Guo, Z.T., and Zhu, R.X.: Ice-volume forcing of East Asian winter Monsoon variations in the past 800, 000 years, Quat. Res., 44, 149-159, https://doi.org/10.1006/qres.1995.1059, 1995.

Ding, Z.L., Ranov, V., Yang, S.L., Finaev, A., Han, J.M., and Wang, G.A.: The loess record in southern Tajikistan and correlation with Chinese loess, Earth Planet. Sci. Lett., 200, 387-400, https://doi.org/10.1016/S0012-821X(02)00637-4, 2002.

Dodonov, A.E, Sadchikova, T.A, Sedov, S.N, Simakova, A.N, and Zhou, L.P.: Multidisciplinary approach for paleoenvironmental reconstruction in loess-paleosol studies of the Darai Kalon section, Southern Tajikistan, Quat. Int., 152, 48-58, https://doi.org/10.1016/j.quaint.2005.12.001, 2006.

EPICA community members: Eight glacial cycles from an Antarctic ice core, Nature, 429, 623-628, https://doi.org/10.1038/nature02599, 2004.

Frechen, M., and Dodonov, A.E.: Loess chronology of the Middle and Upper Pleistocene in Tajikistan, Geol. Rundsch., 87, 2-20, https://doi.org/10.1007/s005310050185, 1998.

Guo, Z.T., Berger, A., Yin, Q.Z., and Qin, L.: Strong asymmetry of hemispheric climates during MIS-13 inferred from correlating China loess and Antarctica ice records, Clim. Past, 5, 21-31, https://doi.org/10.5194/cp-5-21-2009, 2009.

Hao, Q.Z., Wang, L., Oldfield, F., Peng, S.Z., Qin, L., Song, Y., Xu, B., Qiao, Y.S., Bloemendal, J., and Guo, Z.T.: Delayed build-up of Arctic ice sheets during 400,000-year minima in insolation variability, Nature, 490, 393-396, https://doi.org/10.1038/nature11493, 2012.

Hao, Q.Z., Wang, L., Oldfield, F., and Guo, Z.T.: Extra-long interglacial in Northern Hemisphere during MISs 15-13 arising from limited extent of Arctic ice sheets in glacial MIS14, Sci. Rep., 5, 12103, doi: 10.1038/srep12103, 2015.

Huang, W., Chen, J.H., Zhang, X.J., Feng, S., and Chen, F.H.: Definition of the core zone of the "westerlies-dominated climatic regime", and its controlling factors 
during the instrumental period, Sci. Chin. Earth. Sci., 58(5), 676-684, https://doi.org/10.1007/s11430-015-5057-y, 2015.

Jia, J., Gao, F.Y., Xia, D.S., Huang, W., and Chen, F.H.: Moisture variations in arid central Asia and its out-of-phase relationship with the Asian Monsoon during MIS 5: evidence from loess records, J. Quat. Sci., 33, 435-443, https://doi.org/10.1002/jqs.3024, 2018a.

Jia, J., Lu, H., Wang, Y.J., and Xia, D.S.: Variations in the iron mineralogy of a loess section in Tajikistan during the Mid-Pleistocene and Late Pleistocene: Implications for the climatic evolution in central Asia, Geochem. Geophys. Geosyst., 19, 1244-1258, https://doi.org/10.1002/2017GC007371, 2018b.

Jia, J., Xia, D.S., Wang, B., Zhao, S., Li, G.H., and Wei, H.T.: The investigation of magnetic susceptibility variation mechanism of Tien Mountains modern loess: Pedogenic or wind intensity model? Quat. Int., 296, 141-148, https://doi.org/10.1016/j.quaint.2012.10.029, 2013.

Jin, L., Chen, F., Morrill, C., Otto-Bliesner, B., and Rosenbloom, N.: Causes of early Holocene desertification in arid central Asia, Clim. Dyn., 38, 1577-1591, https://doi.org/10.1007/s00382-011-1086-1, 2012.

Kang, S.G., Wang, X.L., Roberts, H.M., Duller, G.A.T., Cheng, P., Lu, Y.C., and An, Z.S.: Late Holocene anti-phase change in the East Asian summer and winter monsoons, Quat. $\quad$ Sci. $\quad$ Rev., https://doi.org/10.1016/j.quascirev.2018.03.028, 2018.

Lawrence, K.T., Herbert, T.D., Brown, C.M., Raymo, M.E., and Haywood, A.M.: High-amplitude variations in North Atlantic sea surface temperature during the early Pliocene warm period, Paleoceanography, 24, PA2218, doi:10/1029/2008PA001669, 2009.

Li, Y., Song, Y.G., Fitzsimmons, K.E., Chen, X.L., Wang, Q.S., Sun, H.Y., Zhang, Z.P.: New evidence for the provenance and formation of loess deposits in the Ili River Basin, Arid Central Asia, Aeolian Research, 35, 1-8, https://doi.org/10.1016/j.aeolia.2018.08.002, 2018.

Li, Y., Song, Y.G., Yin, Q.Z., Han, L., Wang, Y.X.: Orbital and millennial northern 
mid-latitude westerlies over the last glacial period, Climate Dynamics, 53, 3315-3324, https://doi.org/10.1007/s00382-019-04704-5, 2019.

Lisiecki, L. E. and Raymo, M.E.: A Pliocene-Pleistocene stack of 57 globally distributed benthic $\delta^{18} \mathrm{O}$ records, Paleoceanography, 20(2), 1-16, https://doi.org/10.1029/2004PA001071, 2005.

Liu, Q.S., Deng, C.L., Torrent, J., and Zhu, R.X.: Review of recent developments in mineral magnetism of the Chinese loess, Quat. Sci. Rev., 26(3-4), 368-385, https://doi.org/10.1016/j.quascirev.2006.08.004, 2007.

Lu, H.Y. and An, Z.S.: Pretreatment methods in loess-palaeosol granulometry, Chin. Sci. Bull., 42, 237-240, 1997(in Chinese).

Lu, H., Jia, J., Wang, Y.J., Yin, Q.Z., and Xia, D.S.: The cause of extremely high magnetic susceptibility of the S5S1 paleosol in the central Chinese Loess Plateau, Quat. Int., 493, 252-257, https://doi.org/10.1016/j.quaint.2018.05.046, 2018.

Maher, B.A.: Magnetic properties of modern soils and Quaternary loessic paleosol: paleoclimatic implication, Palaeogeogr. Palaeoclimatol. Palaeoecol., 137, 25-54, https://doi.org/10.1016/S0031-0182(97)00103-X, 1998.

Maher, B.A. and Thompson, R.: Paleorainfall reconstructions from pedogenic magnetic susceptibility variations in the Chinese loess and paleosol, Quat. Res., 44, 383-391, https://doi.org/10.1006/qres.1995.1083, 1995.

Ruddiman, W. F., Raymo, M., and McIntyre, A.: Matuyama 41,000-year cycles: North Atlantic Ocean and northern hemisphere ice sheets, Earth Planet. Sci. Lett., 80(1), 117-129, https://doi.org/10.1016/0012-821X(86)90024-5, 1986.

Shackleton, N. J., Berger, A., and Peltier, W.R.: An alternative astronomical calibration of the lower Pleistocene timescale based on ODP site 677, Trans. Edinb. Geol. Soc., 81(4), 251-261, https://doi.org/10.1017/S0263593300020782, 1990.

415 Song, Y., Hao, Q.Z., Ge, J.Y., Zhao, D.A., Zhang, Y., Li, Q., Zuo, X.X., Lü, Y.W., and Wang, P.: Quantitative relationships between magnetic enhancement of modern soils and climatic variables over the Chinese Loess Plateau, Quat. Int., 334-335, 119-131, https://doi.org/10.1016/j.quaint.2013.12.010, 2014. 
Spratt, R.M. and Lisiecki, L.E.: A Late Pleistocene sea level stack, Clim. Past, 12(4), 1079-1092, https://doi.org/10.5194/cp-12-1079-2016, 2016.

Sun, J. M.: Provenance of loess material and formation of loess deposits on the Chinese Loess Plateau, Earth Planet. Sci. Lett., 203, 845-859, https://doi.org/10.1016/S0012-821X(02)00921-4, 2002.

Wang, W., Feng, Z., Ran, M., Zhang, C.: Holocene climate and vegetation changes inferred from pollen records of Lake Aibi, northern Xinjiang, China: A potential contribution to understanding of Holocene climate pattern in East-central Asia, Quat. Int., 311, 54-62, https://doi.org/10.1016/j.quaint.2013.07.034, 2013.

Wang, Y.J., Jia, J., Liu, H., Lu, C.C., Xia, D.S., and Lu, H.: The magnetic susceptibility recorded millennial-scale variability in central Asia during last glacial and interglacial, Geophy. J. Int., 215, 1781-1788, https://doi.org/10.1093/gji/ggy378, 2018.

Wang, Y.J. and Liu, D.B.: Speleothem records of Asian paleomonsoon variability and mechanisms, Chin. Sci. Bull., 61, 938-951, 2016(In Chinese).

Yang, S.L., Ding, F., Ding, Z.L.: Pleistocene chemical weathering history of Asian arid and semi-arid regions recorded in loess deposits of China and Tajikistan, Geochimica et Cosmochimica Acta, 70, 1695-1709, https://doi.org/10.1016/j.gca.2005.12.012, 2006.

Yang, S.L. and Ding, Z.L.: A 249 kyr stack of eight loess grain size records from northern China documenting millennial-scale climate variability, Geochem. Geophys. Geosyst., 15, 798-814, https://doi.org/10.1002/2013GC005113, 2014. 


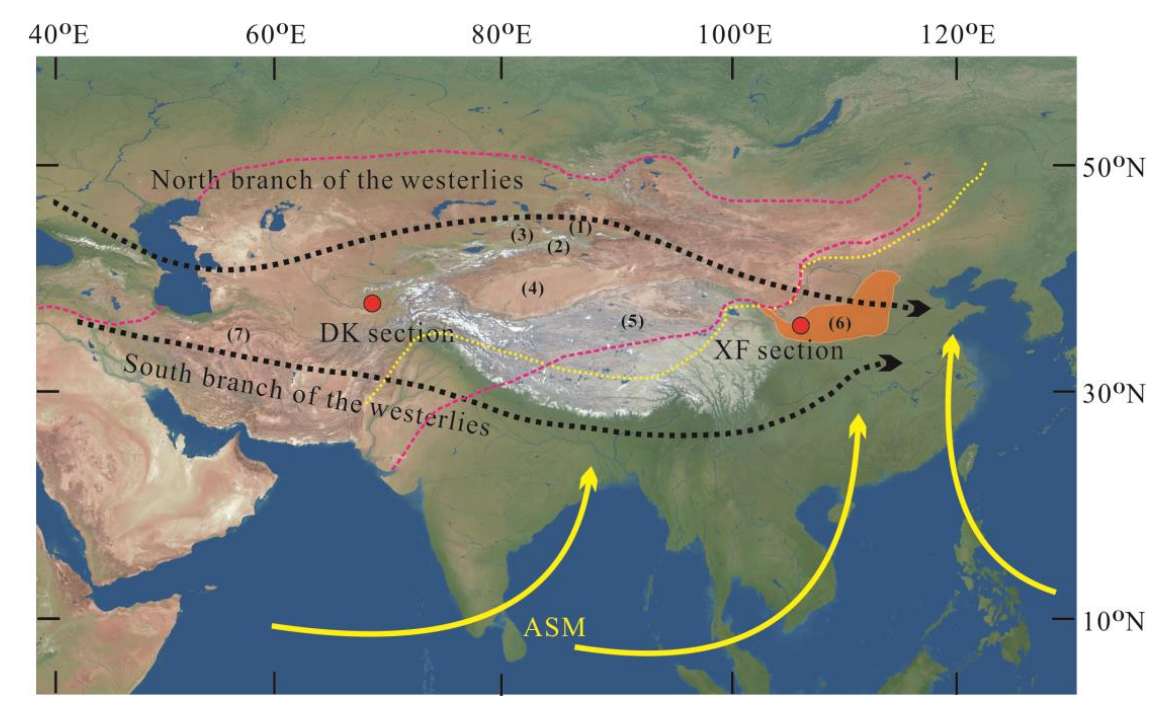

445 Figure 1. RS image of arid central Asia (ACA) and Monsoon Asia with the pink dashed line indicating the present Asian monsoon limit. The area enclosed by the yellow dashed line is ACA (modified from Huang et al., 2015). The number 1-6 are Junggar Basin, Tienshan Mountains, Ili River Basin, Tarim Basin, Tibet Plateau, and Chinese Loess Plateau, as sequences. The range of Chinese Loess Plateau is indicated by orange shadow. 


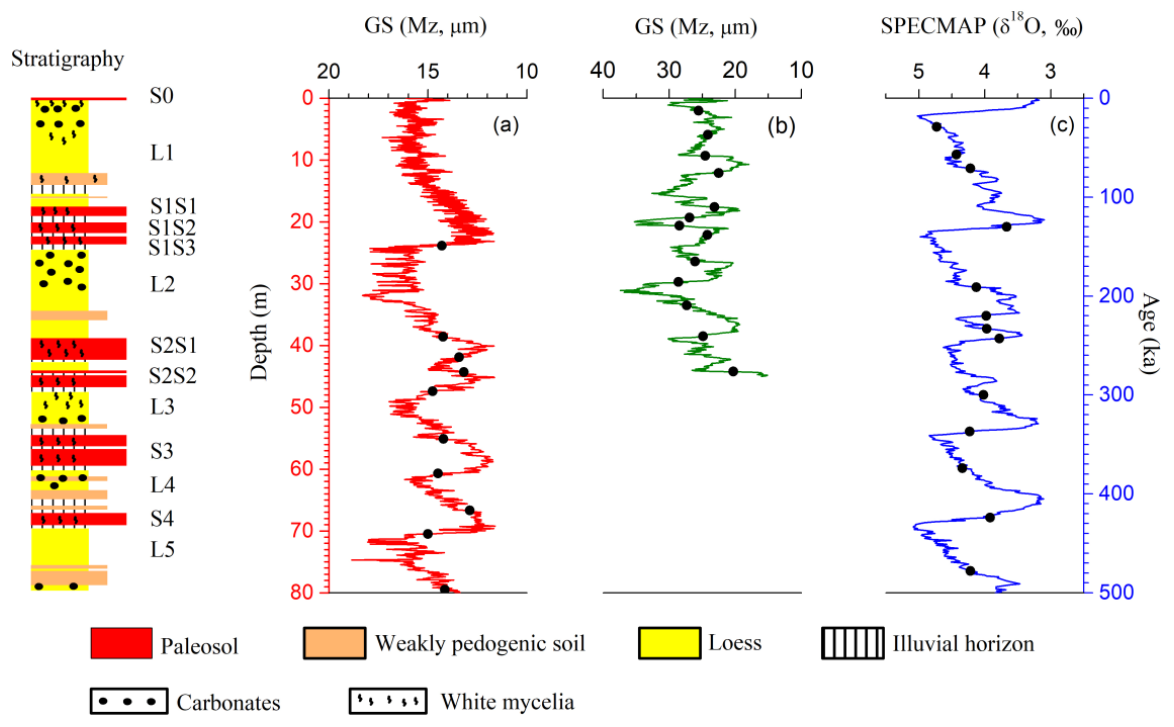

Figure 2. Pedostratigraphy of the DK section (Jia et al., 2018a). The comparisons of

455 climate variations among grain size record in DK section (a), grain size record in XF section (b, Lu et al., 2018), and SPECMAP $\delta^{18} \mathrm{O}$ record (c, Lisiecki and Raymo, 2005).

The black dots in the curves are the location of age control points. 


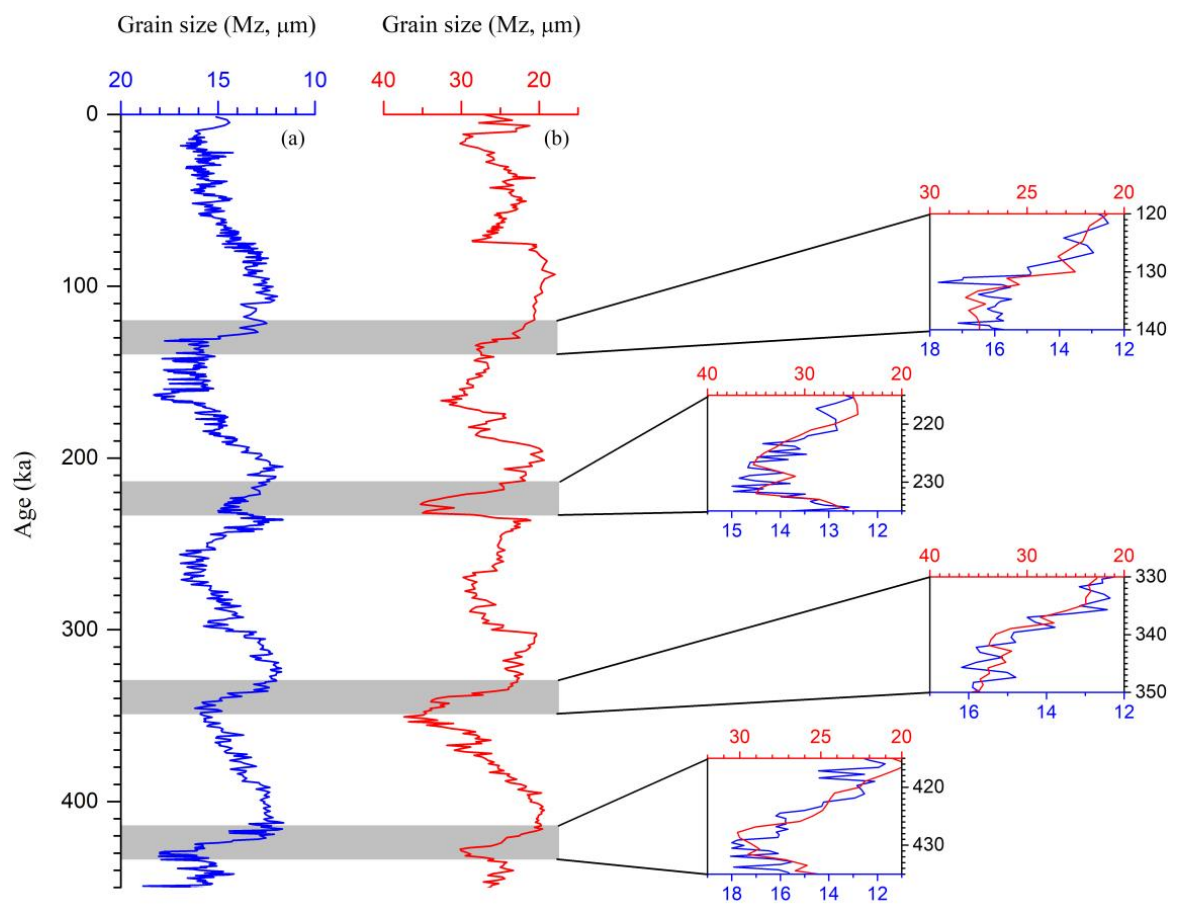

460 Figure 3. Comparison of variations in mean grain-size in the DK section (a, blue curve) and the XF section (b, red curve). The enlarged sub-plots show detailed comparisons of the initiation of four interglacials (MIS 5, 7-1, 9, and 11). 


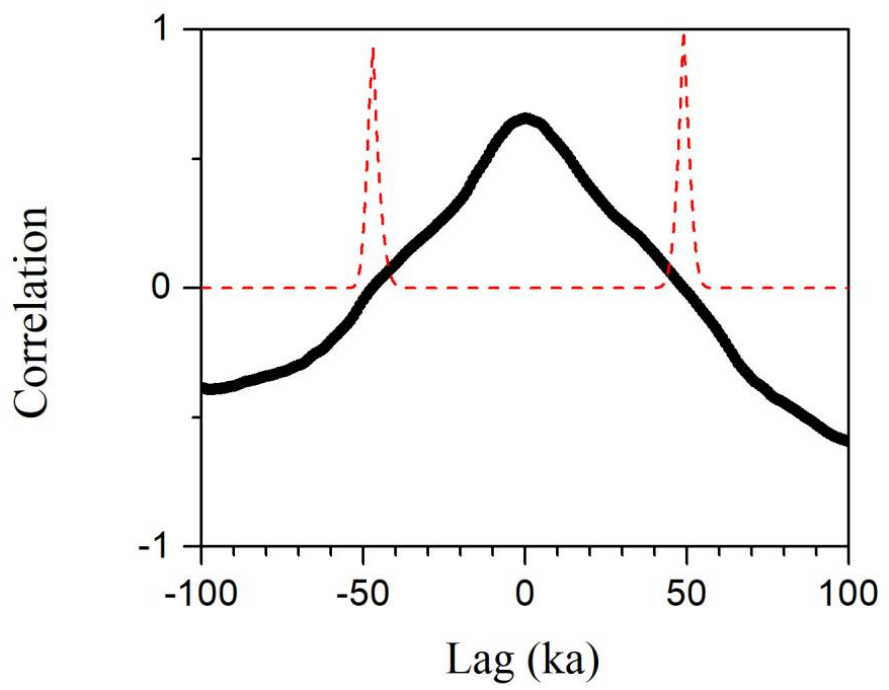

Figure 4. Results of cross-correlation analysis of the grain-size records from the DK and XF sections. The red curve is the $r$ value. 

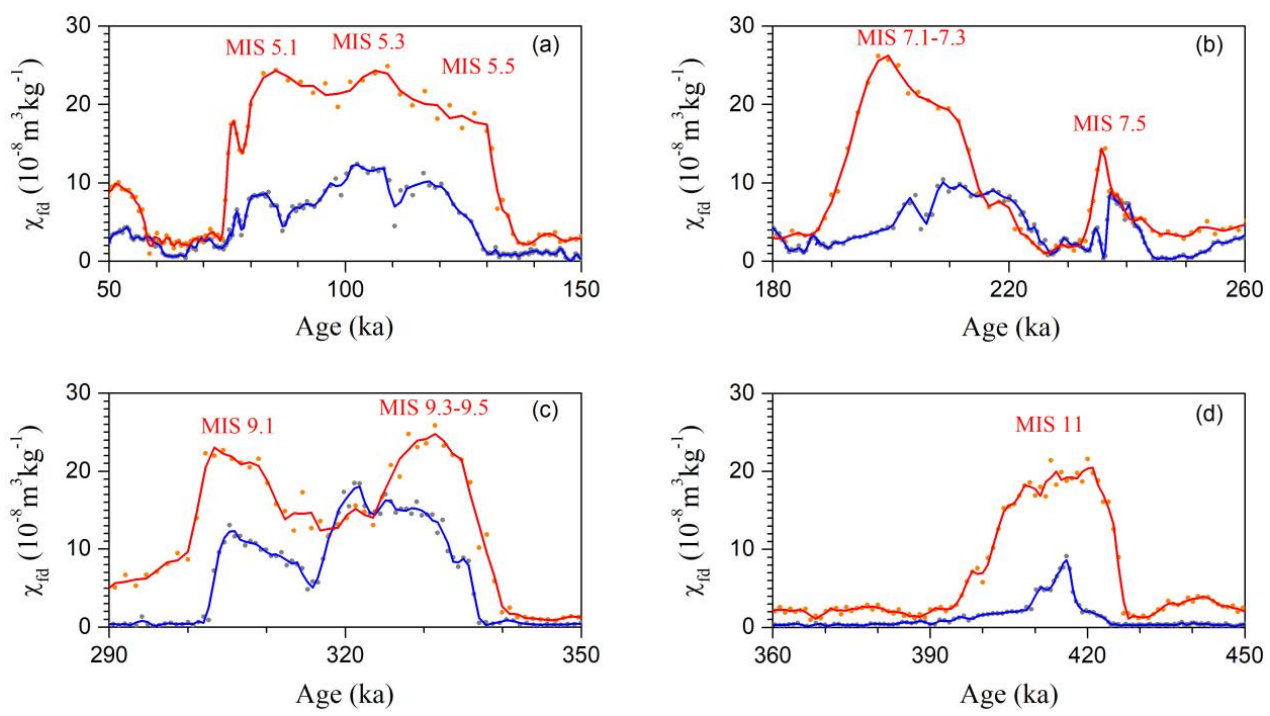

Figure 5. Comparison of records of frequency-dependent magnetic susceptibility $\left(\chi_{\mathrm{fd}}\right)$ for four interglacials in the DK section (blue curve) and XF section (red curve). The dots are the measured data, and the lines are the results of five-point smoothing. (a) Comparison during

475 MIS 5, (b) comparison during MIS 7, (c) comparison during MIS 9, (d) comparison during MIS 11. The data for XF are from Lu et al. (2018). 

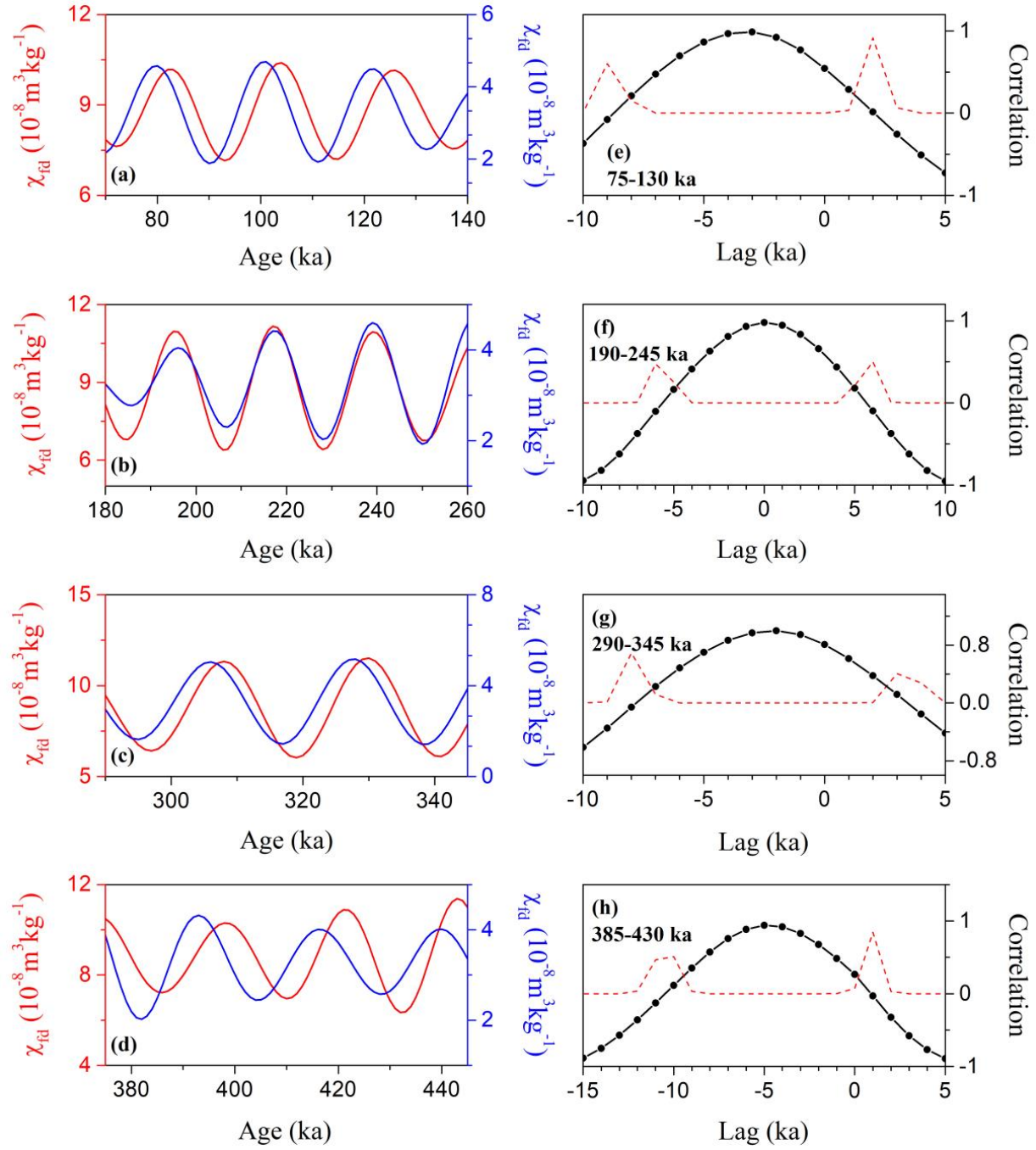

480

Figure 6. Comparison of records of $23 \mathrm{kyr}$ high-pass FFT filtered frequency-dependent magnetic susceptibility $\left(\chi_{\mathrm{fd}}\right)$ during four interglacials. (e-h) Cross-correlation analysis of precipitation components from the DK and XF records. The red curves in figures (e-h) are $\mathrm{r}$ values 


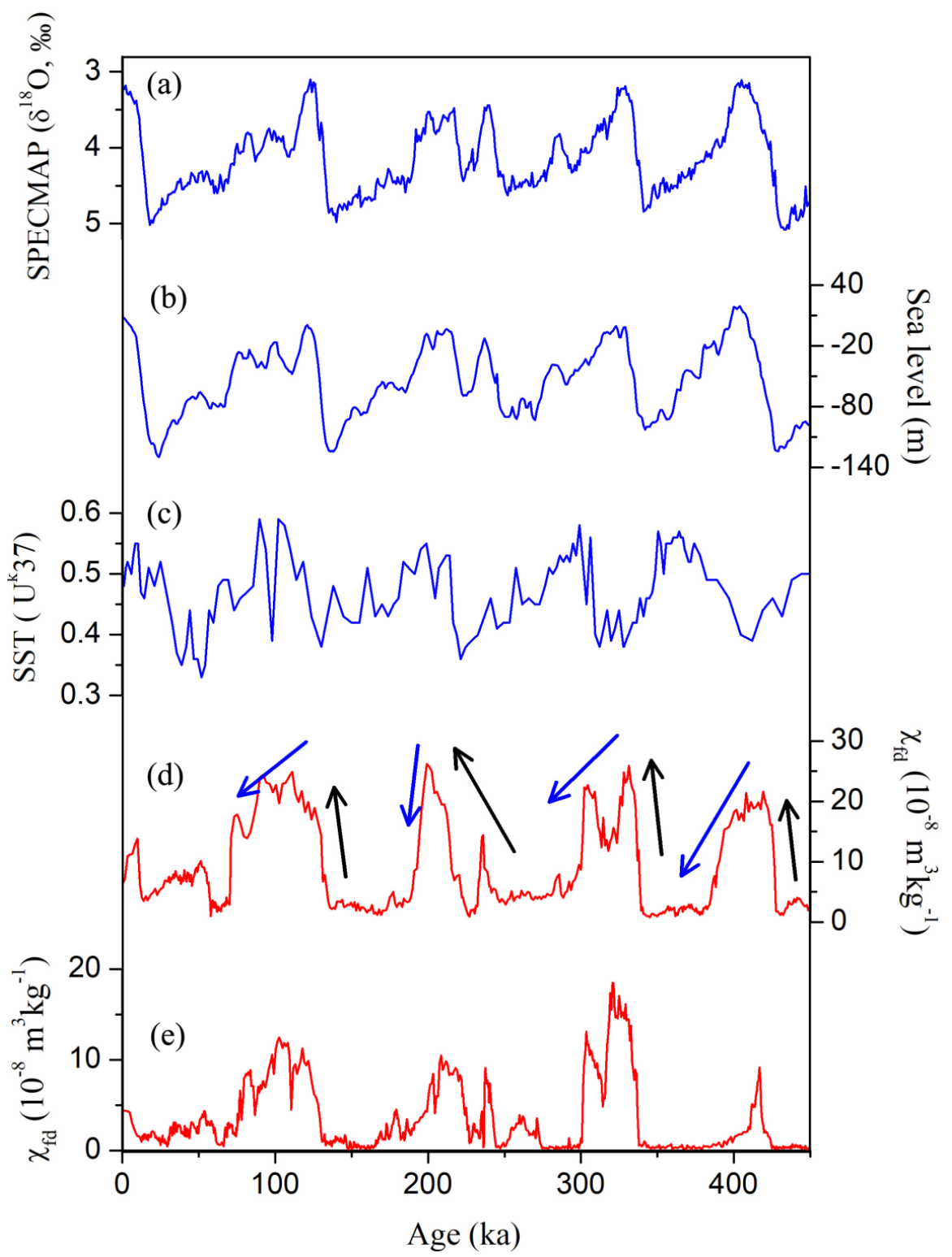

Figure 7. Comparison of patterns of interglacial climatic variability recorded by the marine oxygen isotope record of global ice volume (a, Lisiecki and Raymo, 2005), global average sea level (b, Spratt and Lisiecki, 2016), North Atlantic sea surface temperature (c, Lawrence et al., 2009), and the frequency-dependent magnetic susceptibility record $\left(\chi_{\mathrm{fd}}\right)$ of the Chinese Loess Plateau (d, Guo et al., 2009), and the Tajikistan loess (e). 
https://doi.org/10.5194/cp-2019-117

Preprint. Discussion started: 21 November 2019

(c) Author(s) 2019. CC BY 4.0 License.

Table 1. Age control points and corresponding depths for the DK loess section.

\begin{tabular}{cccccc}
\hline \multirow{2}{*}{ Age $(\mathrm{ka})$} & \multicolumn{2}{c}{ Depth $(\mathrm{m})$} & \multirow{2}{*}{ Depth $(\mathrm{m})$} \\
\cline { 2 - 3 } \cline { 5 - 6 } & DK section & XF section & & DK section & XF section \\
\hline 0 & & 0 & 233 & 44.3 & 20.6 \\
11.5 & & 0.7 & 243 & 47.3 & 22.1 \\
29 & & 2 & 300 & 55.1 & 26.4 \\
57 & & 5.9 & 337 & 60.7 & 29.7 \\
74 & & 9.2 & 374 & 64.7 & 33.5 \\
130 & 23.85 & 12.1 & 424 & 70.5 & 38.5 \\
191 & 38.6 & 17.6 & 478 & 79.5 & 44.2 \\
220 & 41.9 & 19.3 & & & \\
\hline
\end{tabular}

495 